\title{
Analysis of T Cell Responses in Liver Allograft Recipients Evidence for Deletion of Donor-specific Cytotoxic T Cells in the Peripheral Circulation
}

\author{
James M. Mathew, J. Wallis Marsh, Brian Susskind, and T. Mohanakumar \\ Washington University School of Medicine, Department of Surgery, St. Louis, Missouri 63110
}

\begin{abstract}
Analysis of cell-mediated lympholysis in long-term liver allograft recipients indicated that there was a donor-specific unresponsiveness that could not be reversed by the addition of rIL-2 and/or mixed lymphocyte culture supernatant or by nonspecific stimulation of the cultures with PHA. Stimulation of recipient cells with semisyngeneic cells having both donor and thirdparty HLA antigens failed to reveal the presence of cytotoxic $T$ cells (CTL) specific to the donor, whereas the CTL response to third-party antigens remained normal. Removal of B lymphocytes from the responding cell population did not influence the responses. Furthermore, limiting dilution analysis showed that the liver transplant recipients did not have detectable levels of CTL precursors (CTLp) reactive to the donor antigens, whereas their CTLp to third-party antigens remained normal. Donor-specific CTLp were present before and during the early post-transplant period; these cells were eliminated from the peripheral circulation by 10 mo after transplantation. Taken together, these results indicate that there is a deletion of CTLp specific to donor MHC antigens in the peripheral circulation of long-term liver allograft recipients that may account in part for the success of liver transplantation across MHC barriers. ( $J$. Clin. Invest. 1993. 91:900-906.) Key words: mechanism • peripheral tolerance $\cdot$ liver transplantation • cell-mediated lympholysis • limiting dilution analysis
\end{abstract}

\section{Introduction}

Identification of the immunological mechanisms involved in organ allograft rejection and acceptance is still an area of controversy. However, clinical and experimental observations indicate that several different inductive, effector, and regulatory immunological events, either singly or in combination, bring about the rejection or acceptance of allografted organs. Thus, antibodies and cytotoxic T cells (CTL) ${ }^{1}$ against major histocompatibility antigens (MHC) of the allograft (1), antibody-

Address correspondence and reprint requests to T. Mohanakumar, Ph.D., Washington University School of Medicine, Department of Surgery, Box 8109, CSRB 4449, 4939 Children's Place, St. Louis, MO 63110.

Received for publication 11 May 1992 and in revised form $19 \mathrm{Au}$ gust 1992.

1. Abbreviations used in this paper: CML, cell-mediated lympholysis; CTL, cytotoxic T cells; CTLp, CTL precursors; LCL, lymphoblastoid cell lines; LDA, limiting dilution analysis; MLR, mixed lymphocyte reaction; $M R$, maximum release; $S R$, spontaneous release.

J. Clin. Invest.

(C) The American Society for Clinical Investigation, Inc.

0021-9738/93/03/0900/07 \$2.00

Volume 91, March 1993, 900-906 dependent cellular cytotoxicity (2), and delayed-type hypersensitivity reactions (3) are some of the effector mechanisms thought to play important roles in allograft rejection. Mechanisms for the immunological adaptation of the allograft in an antigen-specific manner are thought to include clonal deletion of antidonor alloreactive cells, active suppression of alloreactive clonotypes by suppressor $\mathrm{T}$ cells, and negative modulation of alloreactive $\mathrm{T}$ cells by anticlonotypic immunoglobulins (4-7).

It has been recognized that hepatic allografts are to an extent immunologically "privileged" (8). Both human and animal livers can be transplanted into presensitized recipients without immediate graft injury (8-11). Further, liver grafting induces a state of systemic tolerance specific to donor antigens, such that the recipient will also subsequently accept other organ grafts of the same MHC (11-14). The bulk of experimental animal research in liver transplantation has focused on establishing why hepatic allografts display these unique properties. The anatomical structure of the liver, organ size (14), differences in the expression of class I and II MHC alloantigens (15), secretion of soluble HLA antigens into the general circulation $(13,16)$, elaboration of enhancing anti-Ia antibodies (17), induction of suppressor cells (18), and deletion of donor reactive lymphocytes (19) are some of the reasons proposed to explain the specific tolerance manifested by the animal liver allografts. However, the mechanism of liver allograft acceptance in the human is essentially a matter of conjecture based on extrapolation from findings in animal models. In this communication we present evidence that long-term liver allograft recipients show donor-specific unresponsiveness in the peripheral circulation, as measured by cell-mediated lympholysis (CML) and limiting dilution analysis (LDA). Furthermore, such unresponsiveness could not be overcome by exogenous addition of helper factors or by nonspecific stimulation with mitogens, indicating that there is peripheral tolerance to the donor HLA antigens. Our data also suggest that the peripheral tolerance is mediated by deletion of CTL precursors (CTLp) against the donor HLA antigens.

\section{Methods}

\section{Subjects}

The subjects of these experiments were liver transplant recipients who had well-functioning allografts for $>1 \mathrm{yr}$, unless otherwise mentioned. These patients will be referred to as long-term liver allograft recipients. There were 10 patients, 3 females and 7 males, whose age ranged from 29.9 to $68.9 \mathrm{yr}$ ( mean $46.6 \mathrm{yr}$ ).

Indications for transplantation and the number of patients were chronic active hepatitis $\mathrm{B}, 2$; Budd-Chiari, 1; Caroli's disease, 1; chronic hepatitis $\mathrm{C}, 1$; chronic active non-A non-B hepatitis, 1 ; primary biliary cirrhosis, 1 ; Byler's disease with hepatoma, 1; cryptogenic cirrhosis, 1; and alcoholic cirrhosis, 1 . All liver grafts were primary except for one patient with a second graft who lost his first graft to recurrence of his hepatitis $B$. 
Immunosuppression was with Cyclosporine/Prednisone \pm Azathioprine in eight patients. The other two received immunosuppression with FK506/Prednisone as a part of a randomized trial. One of these patients was later switched to Cyclosporine because of neurotoxicity. Rejection episodes were treated with steroid bolus/recycles and/or OKT3 monoclonal antibody.

The HLA phenotypes of the liver transplant recipients, the donors, and other stimulator cells used in the various experiments are given in Table I. HLA typing was performed using standard microcytotoxicity testing.

\section{Cells and cell preparations}

PBLs. After obtaining informed consent from the patients, $50 \mathrm{ml}$ of heparinized blood was collected and the PBLs were isolated by density gradient centrifugation over Ficoll-Hypaque (Pharmacia Inc., Piscataway, NJ) (20).

Lymphoblastoid cell lines (LCLS). Splenic B lymphocytes or lymph node B lymphocytes from the liver donors were transformed with EBV obtained from the marmoset cell line B95-8 (20). All LCLs were cultured in RPMI 1640 supplemented with $15 \%$ newborn calf serum (Gibco Laboratories, Grand Island, NY), 2 mM L-glutamine, and $100 \mathrm{U} / \mathrm{ml}$ each penicillin and streptomycin.

Stimulator cells. Stimulator cells were LCLs and fresh or cryopreserved spleen cells from the donor and third-party individuals. The third-party individuals were those who did not share HLA antigens

Table I. The HLA Phenotypes of the Recipients and Stimulators of the Study

\begin{tabular}{|c|c|c|}
\hline Subject type & Name/\# & HLA \\
\hline 1. Recipient & JA & A $2 / 29 ;$ B44/-; DR 4/-; DQw3/- \\
\hline Donor & JK & A11/29; B44/51; DR 4/7; DQw2/3 \\
\hline Third & SL & A $33 / 68 ;$ B $17 /-;$ DRw6/10; DQw $2 / 3$ \\
\hline 2. Recipient & CB & Not typed \\
\hline Donor & EJO804 & A $2 / 3$; B $8 / 35$; DR $8 / 11$; DQw3/- \\
\hline Third & EAN395 & A24/-; B 14/27; DR 3/4; DQw2/3/7 \\
\hline 3. Recipient & ME & A $2 / 24$; B $7 / 62$; DR $2 / 11$; DQwl/- \\
\hline Donor & GH & A $2 / 24 ;$ B60/62; DR 4/-; DQw3/- \\
\hline Third & CJY630 & A $1 / 69 ;$ B13/41; DR 7/-; DQw2/- \\
\hline 4. Recipient & $\mathrm{DE}$ & A $2 / 24$; B27/44; DR $1 / 15$; DQw1/- \\
\hline Donor & EAT500 & A $1 / 30 ;$ B $8 / 18 ;$ DR $3 /-;$ DQw2/- \\
\hline Third & EJN778 & A25/29; B51/58; DRw1 1/-; DQw-/- \\
\hline 5. Recipient & BHI & A $2 / 11 ;$ B $8 / 44 ;$ DR $3 / 13 ;$ DQw1/2 \\
\hline Donor & DD1021 & A $1 / 24 ;$ B49/57; DR 4/13; DQw1/3 \\
\hline Third & SL & A33/68; B17/-; DRw6/10; DQw1/- \\
\hline 6. Recipient & MK & A $1 / 3 ;$ B $17 / 55 ;$ DR $3 /-;$ DQw $1 / 2$ \\
\hline Donor & AL & A $1 / 2$; B $8 / 35$; DR $2 / 3$; DQwl/- \\
\hline Third & MM & $\mathrm{A} 11 / 30 ; \mathrm{B} 18 / 62 ; \mathrm{DR} 3 / 9 ; \mathrm{DQw} 2 / 3$ \\
\hline 7. Recipient & $\mathrm{RC}$ & Not typed \\
\hline Donor & MM & A11/30; B18/62; DR 3/9; DQw2/3 \\
\hline Third & CE2953 & A $3 / 31$; B42/51; DR $1 / 12$; DQw1/- \\
\hline Semisyngeneic & SP & A $3 / 30$; B42/62; DR $2 / 10 ;$ DQw1/- \\
\hline 8. Recipient & RE & A $2 /-;$ B39/44; DR 4/-; DQw1/3/6 \\
\hline Donor & DJT397 & A $2 / 29 ;$ B41/45; DR $11 / 14 ;$ DQw-/- \\
\hline Third & EFW145 & A $1 / 68$; B53/58; DR12/15; DQw1/- \\
\hline Semisyngeneic & EJN778 & A25/29; B51/58; DRw11/-; DQw-/- \\
\hline 9. Recipient & EF & A $2 / 32 ;$ B35/44; DRw6/7; DQw1/2 \\
\hline Donor & RR & A $2 / 33$; B35/51; DR $7 / 10$; DQw1/2 \\
\hline Third & EAN407 & A $1 / 24 ;$ B $7 / 8$; DR $2 / 12 ;$ DQw $1 / 3 / 7$ \\
\hline Semisyngeneic & $\mathrm{BH} 2$ & A $1 /-;$ B35/51; DR 1/w8; DQw1/4 \\
\hline 10. Recipient & CS & A $1 /-;$ B $8 / 21$; DR $3 / 7$; DQw2/- \\
\hline Donor & EBZ369 & A $2 /-;$ B $7 / 44 ;$ DR $4 / 15 ;$ DQw $1 / 3 / 6$ \\
\hline Third & CE2953 & A $3 / 31$; B42/51; DR $1 / 12$; DQw1/- \\
\hline Semisyngeneic & DD2047 & A $2 / 3 ;$ B35/44; DR $1 / 13 ;$ DQw1/6 \\
\hline 11. Recipient & FW & A 2/36; B35/-; DR 1/3; DQw1/- \\
\hline Donor & CE2953 & A $3 / 31$; B42/51; DR $1 / 12$; DQw1/- \\
\hline Third & MM & A11/30; B18/62; DR 3/9; DQw2/3 \\
\hline Semisyngeneic & SP & A $3 / 30$; B42/62; DR $2 / 10$; DQw1/- \\
\hline
\end{tabular}

with the donor or the recipient. Before use, stimulator cells were irradiated at 5,000 or 3,000 rads for LCLs and spleen cells, respectively.

$C M L$. The procedure for bulk CML cultures is a modification of the method described earlier (21). Briefly, $1 \times 10^{7}$ recipient PBLs were mixed with irradiated stimulator donor or third-party spleen cells ( 1 $\left.\times 10^{7}\right)$ or LCL $\left(5 \times 10^{6}\right)$ in $20 \mathrm{ml}$ of culture medium in a T-25 culture flask and incubated at $37^{\circ} \mathrm{C}$ in $5 \% \mathrm{CO}_{2}$. After $7 \mathrm{~d}$, recovered cells were counted by trypan blue exclusion and used as effector cells for CTL activity against donor and third-party targets as described below.

${ }^{51}$ Chromium-labeled target cells. Target cells were either LCL or PHA blasts from spleen cells induced with $0.5 \%$ PHA (Wellcome Diagnostics, Dartford, England) for $4 \mathrm{~d}$. On the day of assay, $2 \times 10^{6}$ cells in $250 \mu \mathrm{l}$ of culture medium were incubated with $250 \mu \mathrm{Ci}$ of $\mathrm{Na}^{51} \mathrm{CrO}_{4}$ (New England Nuclear, Boston, MA) for $1 \mathrm{~h}$ at $37^{\circ} \mathrm{C}$. The target cells were then washed four times with RPMI 1640 medium containing 5\% newborn calf serum.

${ }^{51}$ Cr-release CTL assay. Chromium-release assays were conducted by adding graded number of effector cells and $5 \times 10^{3}{ }^{51} \mathrm{Cr}$-labeled target cells (50:1 to 3.125:1 effector/target ratio) in quadruplicate to wells of 96-well round-bottom culture plates in a total volume of $0.2 \mathrm{ml}$ of culture medium. After $5 \mathrm{~h}$ of incubation at $37^{\circ} \mathrm{C}$ in $5 \% \mathrm{CO}_{2}$, culture supernatants were harvested using a Skatron collection system (Skatron, Inc., Sterling, VA) and counted using a gamma counter. Spontaneous release (SR) and maximum release (MR) were determined by adding target cells to wells containing $0.2 \mathrm{ml}$ of culture medium or $1 \%$ Triton X-100, respectively. Percent specific lysis was defined as:

$$
\text { Percent specific lysis }=\frac{\mathrm{CPM}(\text { sample })-\mathrm{CPM}(\mathrm{SR})}{\mathrm{CPM}(\mathrm{MR})-\mathrm{CPM}(\mathrm{SR})} \times 100 .
$$

$L D A$. Estimation of the CTLp frequencies in PBL from liver allograft recipients was performed using LDA as described earlier (21). Briefly, PBL were separated into adherent and nonadherent fractions using a nylon wool column. The nonadherent cells were found to be $>95 \% \mathrm{~T}$ cells as assessed by direct immunofluorescence and were used as responder cells. 24 replicate cultures for each T cell dose were set up in 96-well round-bottom plates. Each culture received irradiated stimulator cells $\left(1 \times 10^{5}\right.$ spleen cells or $\left.5 \times 10^{4} \mathrm{LCL}\right)$ and $5 \times 10^{4}$ irradiated autologous non-T feeder cells in a total of $0.2 \mathrm{ml}$ culture medium containing mixed lymphocyte reaction (MLR) supernatant ( $50 \% \mathrm{vol} /$ $\mathrm{vol}$ ) and $10 \mathrm{U} / \mathrm{ml}$ recombinant IL-2 (Genzyme Corp., Boston, MA). After $7 \mathrm{~d}, 5 \times 10^{3}{ }^{51} \mathrm{Cr}$-labeled target cells were added and a 5-h chromium-release assay was performed as described above.

The mean of 24 SR wells (containing only the labeled target cells, stimulators, irradiated feeder cells, and media) was calculated and three standard deviations were added to the mean to arrive at a value for positive cultures. Data was plotted as $\log$ fraction nonresponding cultures versus $T$ cell dose. Calculation of CTLp frequencies was based on Poisson distribution statistics as described by Lefkovits and Waldmann $(22,23)$ and was determined using a computer program by Taswell (24).

\section{Results}

CML in long-term liver allograft recipients. Analysis of the CTL functions of long-term liver allograft recipients in the CML assay revealed that the donor-specific response was absent compared with easily detectable CTL activity against third-party HLA antigens not shared with the donor (Fig. $1 A$ ). This phenomenon was observed in all seven recipients analyzed. Even increasing the effector/target ratio to 100:1 in the chromium-release assay did not bring about any significant change in the response to the donor, whereas increased specific lysis was observed against the third-party targets (Fig. $1 B$ ). Further, the absence of donor-specific responses was not due to the inability of the donor LCLs to function as effective target cells, as most of the donor cells were also used as third-party 

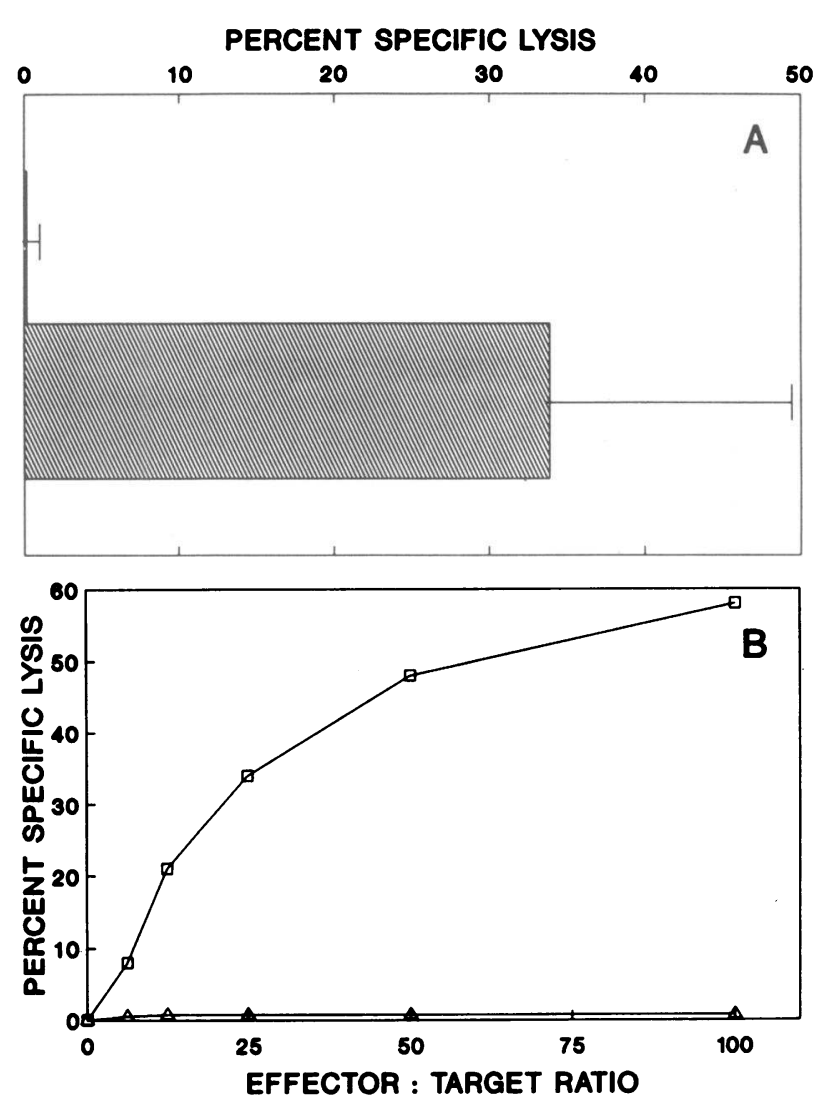

Figure 1. CML unresponsiveness specific to the donor antigens in long-term liver allograft recipients: PBL from liver allograft recipients, who had accepted the graft for $>1 \mathrm{yr}$ were cultured for $7 \mathrm{~d}$ with either donor or third-party LCLs to generate CTL. $(A)$ Data represents the mean of the percentage of specific lysis $( \pm \mathrm{SD})$ at $\mathrm{E} / \mathrm{T}$ ratio of $50: 1$ (recipients RC, RE, EF, JF, BH, CS, and FW). ( $B$ ) CTL responses of a typical CML ( recipient FW) at various $E / T$ ratios.

cells for a different recipient and were found to be competent as antigens and targets. (Part of the data presented in Table II illustrates this point.) Our results thus indicated a specific unresponsiveness in CML to the donor antigens in long-term liver allograft recipients.

Helper functions in long-term liver allograft recipients. To rule out the possibility that the observed donor-specific unresponsiveness was due to a defect in the elaboration of helper factors, CML cultures were supplemented with $25 \mathrm{U} / \mathrm{ml} \mathrm{rIL-2}$ and MLR culture supernatants $(25 \% \mathrm{vol} / \mathrm{vol})$ at their initiation. After the 7-d culture period, however, no improvement in the CTL activity against the donor targets was observed (Fig. 2 ). Furthermore, addition of up to $100 \mathrm{U} / \mathrm{ml} \mathrm{rIL-2} \mathrm{did} \mathrm{not}$ bring about improvement in the specific lysis (data not shown). Similarly, comparable levels of MLR against the donor and third-party antigens were observed in these patients (stimulation index from 5 to 74). These observations demonstrated that the helper cell functions of these patients were not compromised and that CTL unresponsiveness apparently is not merely due to a deficit in the production of helper factors during culture.

Nonspecific stimulation of CML cultures. To determine whether nonspecific stimulation by mitogens could reveal the presence of a donor-specific CTL response, PBL from longterm liver allograft recipients were stimulated with an optimal
Table II. Semisyngeneic Stimulator Cells are Able to Induce Response to Donor Haplotype when Used to Stimulate CML from Another Recipient

\begin{tabular}{cllr}
\hline Responder & \multicolumn{1}{c}{ Stimulator } & Target & Specific lysis \\
\hline \multirow{4}{*}{ RC } & & & $(\%)$ \\
& Donor (MM) & MM & 0 \\
& Third (CE 2953) & CE 2953 & 52 \\
& Semisyngeneic (SP) & SP & 24 \\
& Semisyngeneic (SP) & MM & 1 \\
& Semisyngeneic (SP) & CE 2953 & 12 \\
FW & Donor (CE 2953) & CE 2953 & 0 \\
& Third (MM) & MM & 62 \\
& Semisyngeneic (SP) & SP & 7 \\
& Semisyngeneic (SP) & CE2953 & 1 \\
& Semisyngeneic (SP) & MM & 19 \\
& & & \\
& & &
\end{tabular}

CML assays were carried out in two long-term liver transplant recipients. The SP semisyngeneic cells shared half the HLA antigens with $\mathrm{MM}$ (donor of RC) and the other half with CE 2953 (donor of FW) (Table I). The effector/target ratios were 50:1.

dose of PHA for $2 \mathrm{~d}$ followed by the addition of irradiated donor or third-party LCLs. Subsequent chromium-release assay on day 7 did not show any significant improvement in the specific lysis of labeled donor LCLs, whereas normal CTL activity against third-party target was observed (Fig. 2). Thus, even polyclonal stimulation by a mitogen could not restore the donor-specific responses.

Presentation of the donor HLA antigens on semisyngeneic cells. To test the possibility that donor cells may be exerting a specific modulatory effect on the cultures, the recipient PBL were stimulated with a semisyngeneic LCL that shared some HLA antigens with the donor and some with a third-party. Subsequently, CTL responses to the stimulating cells, donor

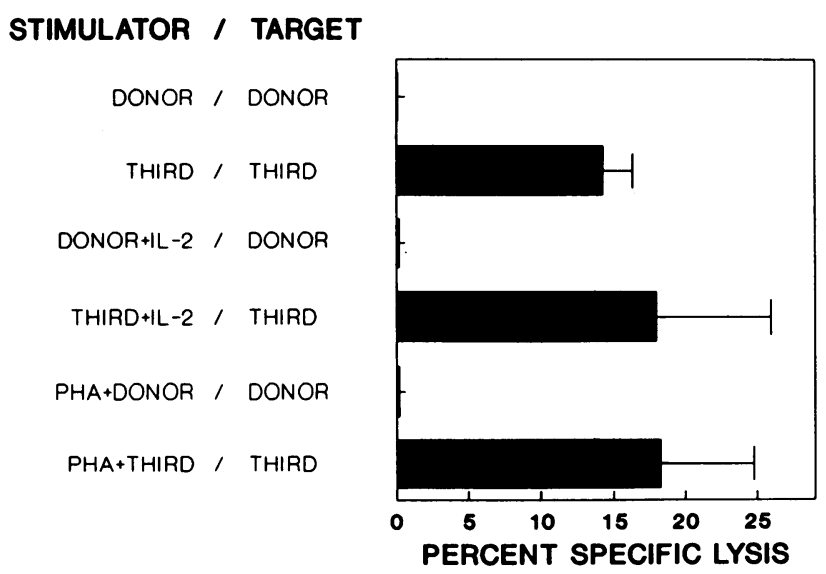

Figure 2. Exogenous addition of helper factors, as well as non-specific stimulation of the responding cells, failed to reveal donor-specific CTLs. CML cultures were carried out against donor and third-party LCLs in the presence of $25 \mathrm{U} / \mathrm{ml}$ rIL-2 plus MLR culture supernatant $(25 \% \mathrm{vol} / \mathrm{vol})$ or the cultures were stimulated with optimal dose of $0.5 \%$ PHA for $2 \mathrm{~d}$ followed by the addition of irradiated donor or third-party LCLs. Data presented are the mean percentage specific lysis $( \pm \mathrm{SD})$ at an $E / T$ ratio of 50:1 from four long-term recipients (RC, EF, BH, and FW). 
STIMULATOR / TARGET

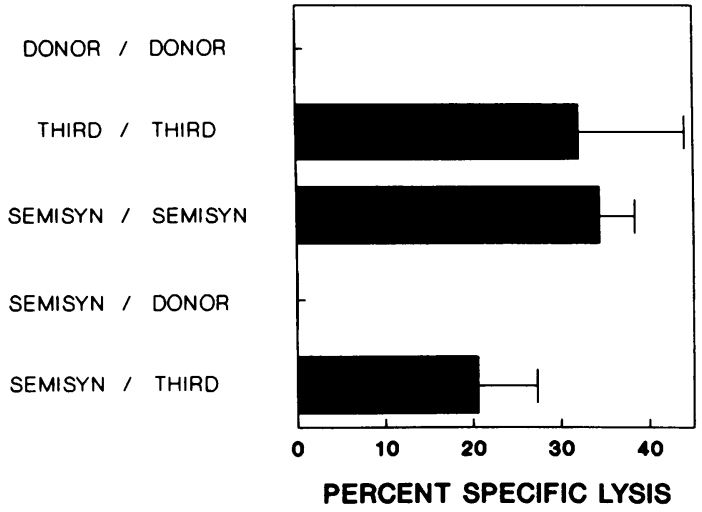

Figure 3. Donor-specific CML responses could not be observed even upon presentation of the donor HLA antigens on semisyngeneic cells (SEMISYN) that shared some HLA antigens with the donor and some with the third party. CML were carried out with the indicated stimulator/target combinations in five long-term liver allograft recipients (RC, RE, EF, CS, and FW). Each bar represents the mean percent specific lysis \pm SD.

cells, and third-party cells were monitored. The results (Fig. 3) demonstrated that presentation of the donor antigens on a semisyngeneic cell could not overcome the specific unresponsiveness, whereas the antithird-party response was not compromised. However, the same semisyngeneic stimulators could induce responses to the donor haplotype when they were used to stimulate CMLs from other recipients (Table II).

Depletion of $B$ cells from the responder cell populations from $C M L$ cultures. It has been reported that a number of liver allograft recipients develop antiidiotypic antibodies specific to antibodies against donor HLA antigens in their sera after liver transplantation (7). To rule out the possibility that in vitrosynthesized antiidiotypic antibodies influenced the development of CTL in our cultures, B cells were depleted from the responder cells by nylon wool adherence before the assays. The nonadherent fraction was found to contain $<1 \%$ B cells by immunofluorescence. Removal of the nylon wool adherent cells did not influence the CTL responses to the third-party; also no improvement in the responses to donor cells was seen (Fig. 4). Similar results were also obtained in LDA irrespective of whether the nylon wool-adherent cells were added back or not (data not shown).

CTLp in long-term liver allograft recipients. Donor-specific unresponsiveness as observed by bulk CML could be due to either suppression or elimination of the donor reactive cells from the peripheral circulation. To distinguish between these two possibilities, LDA were carried out to enumerate the CTLp. The results indicated that there was complete absence of donor-specific CTLp in the peripheral blood of five of six liver transplant recipients tested after $1 \mathrm{y}$ of transplantation (Table III). Further, even in the patient (D.E.) with the residual CTLp to the donor, there was a definite decrease at 13 mo post-transplant from the normal level of CTLs before the allografting $(1: 30,000)$. The unresponsiveness is not due to the immunosuppressive regimen on which the patients are maintained, since the CTLp against third-party HLA antigens remained normal.
Kinetic analysis of the development of the donor-specific unresponsiveness. To monitor at what time point after transplantation the elimination of the donor reactive CTLp in the peripheral blood took place, a kinetic study was initiated in seven patients. Further, such a study should reveal the effects, if any, of the immunosuppression on the patients' responses to the donor antigens. The kinetics studies revealed that normal levels of CTLp could be detected not only on the day of liver transplantation but also during the early posttransplant period (0-5 mo) when the immunosuppressive therapy was at the highest level. Representative results of two patients are shown in Fig. $5 A$ and $B$. More interestingly, the kinetic study completed in one patient (Fig. $5 A$ ), indicated that the donor-specific CTLp disappeared from the peripheral circulation after 10 mo of transplantation, even though the third-party response remained normal (Table III, R.E.).

\section{Discussion}

The mechanisms for immunologic adaptation to liver allografts in an antigen-specific fashion are under investigation in a number of laboratories and are a matter of controversy. Several reasons have been proposed for successful liver transplantation even across positive crossmatch. These include unique architecture of the liver (14), the distribution of HLA antigens (15), the ability of the liver to absorb the antibodies (25), the removal of antibodies by MHC antigens shed from the liver allograft (8), and regulation by idiotype-antiidiotype network (7). Studies at the cellular level in rat and mouse liver allograft models have indicated that donor-specific suppressor cells are induced in long-term survivors (18) or that there is a selective clonal deletion of host antidonor CTL in low rejecting recipients (19). Studies in the human liver transplant recipients have confirmed the finding that donor HLA antigens are upregu-

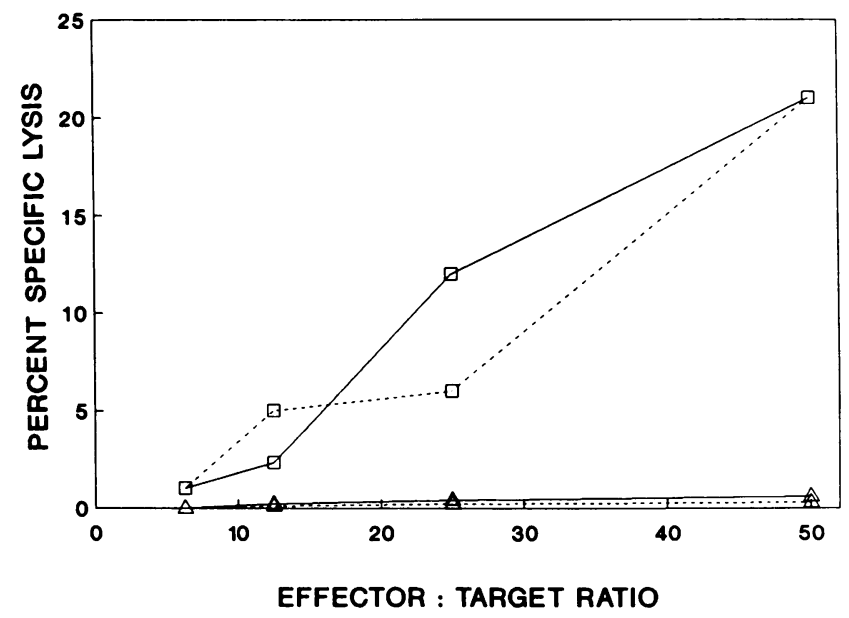

Figure 4. Removal of the B lymphocytes from the responding cell populations could not overcome the donor-specific unresponsiveness. CML were carried out with the whole peripheral blood lymphocytes (solid lines) or after removing the nylon wool column adherent cells (dotted lines) in recipient FW. The nylon wool nonadherent cells were $>95 \% \mathrm{~T}$ cells as assessed by direct immunofluorescence. The triangles represent the donor and the squares indicate the third-party responses. 


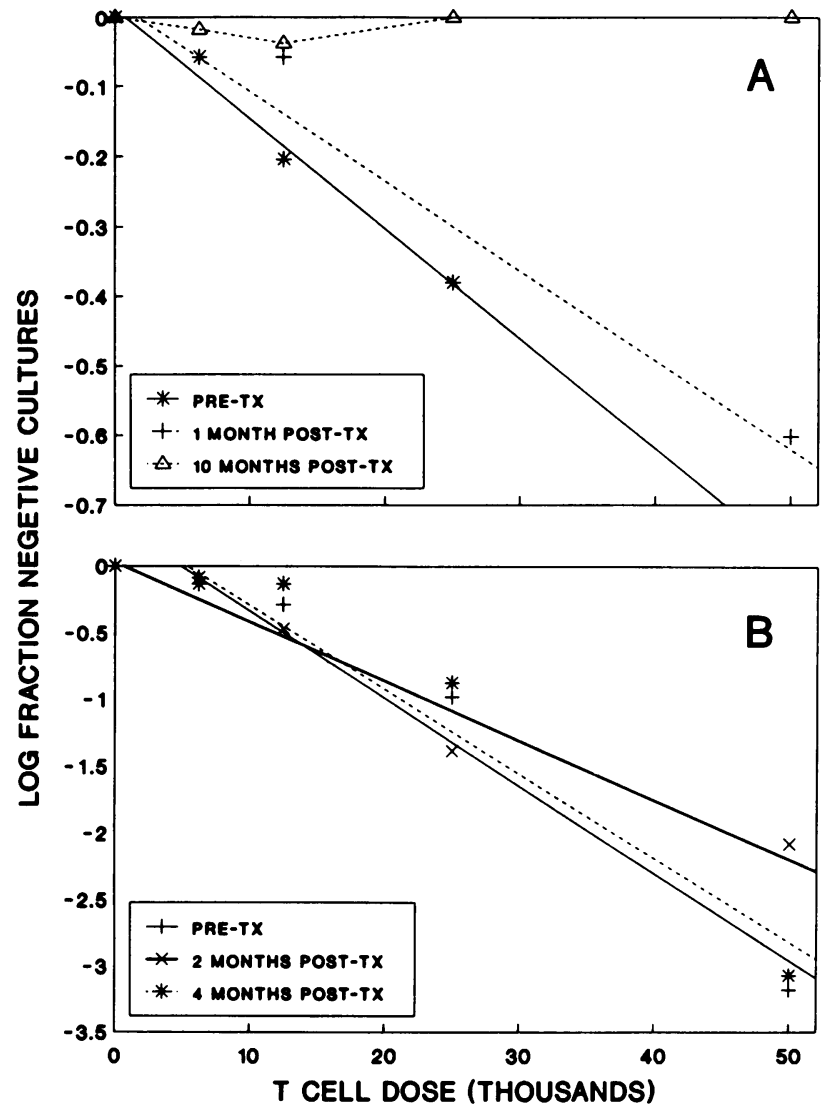

Figure 5. Kinetics of the donor-specific CTLp in liver transplant recipients. The CTLp frequencies in patient $\operatorname{RE}(A)$ were pretransplant, 1:28,000; 1 mo posttransplant, 1:59,000; and 10 mo posttransplant, nil. Similarly, the donor-specific CTLp frequencies in the patient $C B$ (B) were pretransplant, 1:28,000; 1 mo posttransplant, 1:17,000; and 4 mo posttransplant, 1:16,000.

lated in the allograft $(16,26)$ and subsequently shed into the general circulation and that this may be modulating the immune response (16). Further, the presence of antiidiotypic anti-

Table III. Cytotoxic T Lymphocyte Precursors in the PBL of Long-Term Liver Allograft Recipients

\begin{tabular}{lcc}
\hline & \multicolumn{2}{c}{ CTLp per $10^{6} \mathrm{~T}$ cells* } \\
\cline { 2 - 3 } $\begin{array}{c}\text { Allograft } \\
\text { recipient }\end{array}$ & Donor & Third \\
\hline ME & ND $^{\ddagger}$ & $18(11-26)^{\S}$ \\
JA & ND & $111(72-142)$ \\
MK & ND & $250(166-333)$ \\
BH & ND & $111(72-142)$ \\
RE & ND & $27(18-37)$ \\
DE & $6(3-10)$ & $50(43-58)$ \\
\hline
\end{tabular}

CTLp frequencies against the donor and third-party LCLs were estimated by LDA. * Nylon wool column nonadherent cells were considered to be T cells. ${ }^{\ddagger}$ The CTLp could not be detected (ND) at the maximum dose of $T$ cells used $(100,000$ per well) for LDA against donor. ${ }^{\$}$ Values in the parenthesis indicate the $95 \%$ confidence interval. bodies has been documented, especially during the early phase of posttransplant period (7).

The results presented here clearly indicate that there is a donor-specific unresponsiveness in CML in long-term liver allograft recipients. This unresponsiveness is not a nonspecific phenomenon caused by the immunosuppression on which the patients are maintained, as the CTL response to third-party antigens remained within a normal level (Figs. 1-4 and Tables II and III ). Further, in the kinetic studies, normal donor and third-party responses were detected in the early phase of the posttransplant period when the immunosuppressive regimen was at its maximum (Fig. 5).

Exogenous addition of $25 \mathrm{U} / \mathrm{ml}$ IL-2 and MLC supernatant $(25 \% \mathrm{vol} / \mathrm{vol})$ to the CML cultures did not induce CTL development (Fig. 2). Increasing the concentration of the IL-2 up to $100 \mathrm{U} / \mathrm{ml}$ also did not bring about the abrogation of the specific unresponsiveness. Thus, the mechanism of absence of CML responses is different from the CML unresponsiveness observed in renal allograft tolerance (27), where addition of exogenous IL-2 to cultures could overcome the specific unresponsiveness. Moreover, normal levels of MLR responses were obtained in the long-term liver transplant recipients. Further, only the third-party response and not the donor-specific response was obtained when the responding recipient cells were presented with the two types of antigens on a single semisyngeneic stimulator cell (Fig. 3). These results strongly argue against a defect in the helper cell functions in the liver allograft recipients.

Previous studies from our laboratories (7), as well as unpublished results with the sera from some of the present liver transplant subjects, indicate that donor-specific antiidiotypic and anticlonotypic antibodies are produced in liver patients, especially during the early phase of the posttransplant period. In this context, it was possible that antiidiotypic and anticlonotypic antibodies, secreted in vitro by the B cells in the responding recipient cell population, might be downregulating the cultures. Therefore, the B cells were depleted from the responder cells before the CML assay. Likewise, non- $T$ feeder cells were not added back to LDA cultures. In both experiments, no influence of nylon wool adherent cells was observed, indicating the absence of regulatory activity by in vitro synthesized antiidiotypic or anticlonotypic antibodies (Fig. 4).

It may be possible that the donor cells are exerting a specific modulatory effect on the CML cultures, thus masking the responses to the donor HLA antigens. To test this, the recipient PBL were stimulated with the donor HLA antigens on semisyngeneic cells. All five cases studied still failed to elicit donor-specific CTL functions (Fig. 3). One patient, however, showed donor-specific CTL responses at $15 \mathrm{mo}$, but not at 21 mo posttransplantation, when stimulated with semisyngeneic LCL but not with the donor LCL. Thus, there may be a transition period before the onset of deletion, during which donor-specific unresponsiveness can be bypassed by presenting donor HLA antigens on semisyngeneic cells. In all the cases, the CTL response against HLA antigens immunologically unrelated to the donor was not suppressed when both sets of determinants were presented on the same semisyngeneic cell. This finding is evidence against the role for both veto cells (28) and suppressor cells (29) affecting antidonor unresponsiveness in CML cultures.

In marked contrast to the studies of Vanderkrchhove et al. (30), who examined kidney allograft acceptance, nonspecific 
stimulation of the cultures with PHA did not reveal the presence of donor-specific CTL in the peripheral circulation of long-term liver allograft recipients. The absence of PHA-inducible donor-specific response suggested that anergy (31) was not the cause of the observed unresponsiveness. However, anergy could not be totally ruled out as we did not screen for the absence of putative donor-specific T cell receptors. Similarly, if active suppression of recipient CTL were occurring, one would expect a measurable response at low $\mathrm{T}$ cell doses in the LDA $(22,23)$. Furthermore, presentation of the donor antigens on semisyngeneic cells could not overcome the donor-specific unresponsiveness (Fig. 3). In addition, depletion of the non-T cells from the responder cells in CML and LDA did not restore anti-donor responsiveness, indicating that these cells were not a cause of suppression (Fig. 4). The results of these experiments suggest that neither active suppression nor anergy can explain recipient unresponsiveness to the donor antigens.

The results of the LDA are more striking (Table III). No donor-specific CTLp were found in the peripheral circulation of five out of six liver allograft recipients after $1 \mathrm{yr}$ of transplantation, and the one exceptional case might be only a matter of delayed kinetics. Further, in the kinetics studies, normal donor and third-party responses were detected in the early phase of the posttransplant period even when the immunosuppressive regimen was at its maximum (Fig. 5, $A$ and $B$ ). More interestingly, the kinetics studies completed in one patient showed that the donor-specific CTLp disappeared after 10 mo of transplantation. Thus, the LDA studies clearly indicated that the donorspecific CTLp were deleted from the peripheral circulation of long-term liver transplant recipients.

It should be noted that the present study has looked at the donor-specific responses of liver transplant recipients only in the peripheral circulation. It is possible that the specific $T$ cells are sequestered in the graft itself. However, we have not been able to culture donor-specific $\mathrm{T}$ cells from liver biopsies taken at times other than during rejection episodes (unpublished observations). This suggests that activated donor-specific cells are either deleted or depleted in successfully allografted livers also.

Taking all the observations together, the mechanism of unresponsiveness appears to be the deletion of donor reactive CTLp from the peripheral circulation of liver transplant recipients who have accepted the allograft for $>1 \mathrm{yr}$. The unresponsiveness was not a nonspecific phenomenon caused by the immunosuppressive therapy, since good third-party responses were consistently observed in all the patients studied and normal levels of donor reactive CTLs were found during the early phase of the posttransplant period in the subjects of the kinetics study. A number of direct and indirect data presented argue that the unresponsiveness is not due to defective helper functions. Further, results of experiments where B lymphocytes were depleted from CML and LDA indicated that the in vitro synthesized antiidiotypic antibodies or anticlonotypic antibodies were not downregulating the donor-specific responses in cultures. Similarly, any role for veto cell and suppressor cell activities can be ruled out, as normal CTL activity was observed against the third-party antigens but not against the donor antigens when both sets of determinants were presented on the same semisyngeneic cell. This finding, as well as the observation that nonspecific stimulation with PHA could not restore donor-specific response, indicated that anergy was not operating in this unresponsiveness. The profile of the LDA and esti- mation of CTLp clearly indicated that the unresponsiveness was determined by deletion of donor reactive cells. Thus, a long-term goal in transplantation biology, i.e., deletion of specific CTLp against the donor antigens, has been achieved in liver transplantation. Understanding the mechanism of this deletion will aid us in our approach to complete acceptance of all organ transplants.

\section{Acknowledgments}

We thank Drs. T. Hansen, N. Poindexter, and Mr. B. Duffy for discussion and review of the manuscript and Mrs. B. Glasscock for secretarial assistance.

This work was supported by National Institute of Health AI28356.

\section{References}

1. Charpentier, B. 1983. Mechanisms of rejection: update 1982. Transplant. Proc. 15:259-263.

2. Dumble, L. J., I. M. MacDonald, and P. Kincaid-Smith. 1980. Human renal allograft rejection is predicted by serial determination of antibody-dependent cellular cytotoxicity. Transplantation (Baltimore). 29:30-34.

3. Loveland, B., R. H. Ceredig, and M. Hogarth. 1981. The key role of Lyt-1+ cells in skin graft rejection in the mouse. Transplant. Proc. 13:1079-1081.

4. Cohen, D. J., H. M. Lee, and T. Mohanakumar. 1985. Mechanisms of CML hyporesponsiveness in longterm renal allograft recipients. Hum. Immunol. 14:279-286.

5. Liburd, E. M., V. Pazderka, T. Kovithavangs, and J. B. Dossetor. 1979. Evidence for suppressor cells and reduced CML induction by the donor in transplant patients. Transplant. Proc. 10:557-561.

6. Twuyver, E., W. M. Kast, R. J. D. Mooijaart, J. M. Wilmink, C. J. M. Melief, and L. P. DeWaal. 1989. Allograft tolerance induction in adult mice associated with functional deletion of specific CTL precursors. Transplantation (Baltimore). 48:844-847.

7. Mohanakumar, T., C. Rhodes, G. Mendez-Picon, M. W. Flye, and H. M. Lee. 1987. Antiidiotypic antibodies to human major histocompatibility complex class I and II antibodies in hepatic transplantation and their role in allograft survival. Transplantation (Baltimore). 44:54-58.

8. Calne, R. Y., R. A. Sells, J. R. Pena, D. R. Davis, P. R. Millard, B. M Herbertson, R. M. Binns, and D. A. L. Davies. 1969. Induction of immunologic tolerance by porcine liver allografts. Nature (Lond.). 223:472-476.

9. Demetris, A. J., and B. H. Markus. 1989. Immunopathology of liver transplantation. Crit. Rev. Immunol. 9:67-92.

10. Roser, B. J., N. Kamada, F. Zimmermann, and H. S. Davies. 1987. Immunosuppressive effect of experimental liver allografts. In Liver Transplantation: The Cambridge-King's College Hospital Experience. R. Calne, editor. Grune \& Stratton, London.

11. Kamada, N. 1985. The immunology of experimental liver transplantation in the rat. Immunology. 55:369-389.

12. Kamada, N., and D. Wright. 1984. Antigen specific immunosuppression induced by liver transplantation in the rat. Transplantation (Baltimore). 38:217221.

13. Kamada, N., G. Brons, and H. F. Davies. 1980. Fully allogeneic liver grafting in rats induces a state of systemic nonreactivity to donor antigens. Transplantation (Baltimore). 29:429-431.

14. Flye, M. W., B. Duffy, D. Phelan, L. E. Ratner, and T. Mohanakumar 1990. Protective effects of liver transplantation on a simultaneously transplanted kidney in a highly sensitized patient. Transplantation (Baltimore). 50:10511054.

15. Hartz, J. T., S. K. S. So, G. A. Keller, R. Hoffman, N. L. Ascher, and R. L. Simmons. 1985. Immunospecific lymphocyte-mediated injury of isolated hepatocytes. Transplant. Proc. 17:606-607.

16. Davies, H., S. G. Pollard, and R. Y. Calne. 1989. Soluble HLA antigens in the circulation of liver graft recipients. Transplantation (Baltimore). 47:524527.

17. Kamada, N., T. Shinomiya, T. Tamaki, and K. Ishiguro. 1986. Immunosuppressive activity of serum from liver grafted rats. Transplantation (Baltimore). 42:581-587.

18. Tsuchimoto, S., A. Kakita, J. Uchino, K. Mizuno, H. Fujii, Y. Matsuno, T. Natori, and M. Aizawa. 1987. Mechanism of tolerance in rat liver transplantation: evidence for the existence of suppressor cells. Transplant. Proc. 19:514-518.

19. Kamada, N., and T. Shinomiya. 1985. Clonal deletion as the mechanism of abrogation of immunological memory following liver grafting in rats. Immunology. 55:85-90. 
20. Coligan, J. E., A. Kruisbeek, D. Margulies, E. Shevach, and W. Strober. 1991. Current Protocols in Immunology. Wiley Interscience, Brooklyn, NY.

21. Hadley, G. A., D. Phelan, B. Duffy, and T. Mohanakumar. 1990. Lack of T cell tolerance of noninherited maternal HLA antigens in normal humans. Hum. Immunol. 28:373-381.

22. Lef kovits, I., and H. Waldmann. 1984. Limiting dilution analysis of the cells of immune system I. The clonal basis of the immune response. Immunol. Today. 5:265-268.

23. Waldmann, H., and I. Lef kovits. 1984. Limiting dilution analysis of cells of the immune system II. What can be learnt? Immunol. Today. 5:295-298.

24. Taswell, C. 1987. Limiting dilution assays for the separation, characterization, and quantitation of biologically active particles and their clonal progeny. In Cell Separation: Methods and Selected Applications. T. G. Pretlow, and T. P. Pretlow, editors. Academic Press Inc., Orlando, FL.

25. Houssin, D., J. Gugenheim, B. Bellan, M. D. Brunaud, M. Gigou, M. Charra, S. Crougneau, and H. Bismuth. 1985. Absence of hyperacute rejection in liver allografts in hypersensitized rats. Transplant. Proc. 17:293-295.

26. Demetris, A. J., S. Lasky, D. H. Van Thiel, T. E. Starzl, and T. Whiteside. 1985. Induction of DR/IA antigens in human liver allografts. Transplantation (Baltimore). 40:504-509.
27. Grailer, A. P., H. W. Sollinger, T. Kawamura, and W. J. Burlingham. 1991. Donor-specific cytotoxic T lymphocyte hyporesponsiveness following renal transplantation in patients pretreated with donor-specific transfusions. Transplantation (Baltimore). 51:320-324.

28. Uberti, J., F. Martilotti, T.-H. Chou, and J. Kaplan. 1992. Human lymphokine activated killer (LAK) cells suppress generation of allospecific cytotoxic T cells: implications for use of LAK cells to prevent graft-versus-host disease in allogeneic bone marrow transplantation. Blood. 79:261-268.

29. Susskind, B. M. 1986. Regulatory mechanisms in cytotoxic T lymphocyte development. III. Induction, specificity, and genetic restriction of an in vitro suppressor T cell. Cell. Immunol. 101:524-533.

30. Vandekerckhove, B., G. Datema, F. Koning, E. Goulmy, G. Persijn, J. Van Rood, F. Claas, and J. deVries. 1990. Analysis of the donor-specific cytotoxic $T$ lymphocyte repertoire in a patient with a long term surviving allograft: frequency, specificity, and phenotype of donor-reactive T cell receptor (TCR)-alpha-beta+ and TCR-gamma-delta+ clones. J. Immunol. 144:1288-1294.

31. Schutze, M., P. Langlade-Demoyen, and C. Leclere. 1992. Alloantigenspecific regulation of cytotoxic $T$ cell responses is mediated through the induction of clonal anergy of CD8+ T cells. Eur. J. Immunol. 22:387-392. 